\title{
THE EFFECTS OF REDLINING IN SINGAPORE'S RED-LIGHT DISTRICT
}

\author{
Mo ZHENG ${ }^{1, *}$ \\ ${ }^{1}$ Department of Real Estate and Construction Management, School of Architecture and the Built Environment, \\ KTH-Royal Institute of Technology, Stockholm, Sweden
}

Received 2 November 2017; accepted 23 April 2018

\begin{abstract}
There are cities or regions with legal red-light districts in both developed and developing countries, but there are also regions or countries with no clear rules regarding prostitution. Financing issues in red-light districts represent another aspect rarely examined in the academic world. Most research studies about redlining are focused on racial or poverty levels, but this paper investigates it in relation to moral issues concerning vice activities. The objectives of this paper are to firstly analyse the red-light phenomenon in relation to sales prices and rent prices, secondly to test the redlining effect on property markets. This paper contributes to the current academic literature. The research setting of this paper is Geylang, Singapore, a place known for its centralized location, 24/7 stores, historic locales and prostitution-related business. The results indicate that the existence of Singapore's red-light district has a negative effect on both residential purchase prices and rent levels. The results also indicate that there exists a redlining effect since the home prices have a much higher discount than rents.
\end{abstract}

Keywords: redlining, housing market, hedonic regression, mortgage financing, empirical analysis.

\section{Introduction}

Numerous empirical studies have investigated a rich variety of aspects of housing characteristics over the years, including structural, neighbourhood and locational attributes in the process of property valuation. Urban geographers, in the larger picture, take human behaviour into consideration. One major aspect, the urban social environment, has played an increasingly important role not only in the real estate industry but also in the field of sociology. As for the urban social environment, variables such as safety level, crime rate and racial clustering have been studied. One grey area, however, has largely escaped attention, namely prostitution and its direct and indirect effects on the surrounding so-called red-light district.

There are cities or regions with legal red-light districts in both developed and developing countries, but there are also regions or countries with no clear rules regarding prostitution. It is undeniable than street prostitution affects the entire surrounding area in certain ways. Most research articles on red-light districts are written in the fields related to sociology, crime, trafficking and human rights, but few are written in relation to the real estate industry. Financing issues in red-light districts represent another aspect rarely examined in the academic world. Research on the granting of mortgages in controversial regions should include an examination of redlining. As discussed in more depth in the literature review section (Section 1) of this paper, redlining is the exclusion of certain financial services that provided in the specific area for various reasons. Many papers investigate the causations from the view of racial and poverty level, but this paper examines it in relation to moral issue, which are the prostitution activities.

The objectives of this paper are to analyse the redlining phenomenon in relation to sales prices and rent prices in the study area and to test the redlining effect on property markets; contribute to the current academic literatures. The research setting of this paper is Geylang, Singapore, a place known for its centralized location, 24/7 stores, historic locales and prostitution-related business.

To fulfil these objectives, this paper examines 1,414 transaction records of condominiums and apartments developed by private companies that were caveat lodged by actual processed law firms from March 2014 to March 2016. In addition, 914 pieces of rental data posted by certified residential agents are collected from Propertyguru, one of the largest real estate websites, as well as interviews and realty practices from financing institutions, to find out the spillover effects of the red-light district in Geylang,

*Corresponding author. E-mail: mo.zheng@abe.kth.se 
Singapore, on prices in both purchase and rental markets for residential properties and on financing methods.

The results indicate that the existence of Singapore's red-light district has a negative effect on both residential purchase prices and rent levels. The results also indicate that there exists a redlining effect since the home prices have a much higher discount than rents. This study may provide developers, home buyers and tenants with a better understanding of the current housing market in this grey area and may be used as a guide for institutional or individual investors.

This paper is organized as follows: Section 1 describes the literature review of red-light district and redlining applications. Section 2 introduces the study area and presents two hypotheses. The methodology of hedonic regression is outlined in Section 3. The empirical analysis, including data and results, is presented in Section 4. The findings and policy applications are summarized in the last section.

\section{Literature review}

\subsection{Nature of Red-light district}

Red-light zones are recognized as a cluster of retail service, just like other antiques district or specialist districts (Ryder, 2004). Those areas are often found in one or in limited number of locations in older cities with a long history. Examples of such areas can be found alongside business centres in major metropolitan areas, but also in connection to gateways to cities such as railway stations, bus terminals and harbour areas. In some cities, red-light areas are scattered outside the cities in the suburbs or along the highways, while in other cities the red-light areas are more concentrated to specific districts and aiming for certain types of markets (See Del Casino Jr \& Hanna, 2003; Hubbard, 2004; Ryder, 2004).

In most countries, prostitution is considered illegal; however in the Netherlands, Germany, the state of Nevada (US) and Singapore, the authorities allow licensed brothels to operate with specific restrictions. But countries such as Japan and Thailand, which officially have prohibited prostitution are still known for their red-light districts and related businesses. Thus, the effects of those anti-prostitution laws are under debate (Neave, 1988; Jakobsson \& Kotsadam, 2013).

Other topics of red-light districts include aspects such as landscapes of street prostitution in Western European cities (Ashworth, White, \& Winchester, 1988), issues of social and cultural exclusion (Winchester \& White, 1988), workforce components of the industry (Hubbard \& Whowell, 2008), historical and regulation updates of red-light district (Aalbers \& Deinema, 2012), economic gap of cross country prostitution (Marttila, 2008).

\subsection{Redlining application}

Redlining is a form of place-based exclusion of certain financial services such as mortgages. The existence of redlining is widely documented in the United States (Aal- bers, 2005a; Aalbers, 2009) and can be considered as a form of lending discrimination.

Early research studies focused on the poor or the nonwhites (Holloway, 1998); the racial and income composition in certain neighbourhoods in the United States (Ross \& Tootell, 2004); social discriminations (Nesiba, 1996) and lack of confidences of a certain neighbourhood and denied the loan applicants, which reflect a dynamic urban decay in some cases (Kantor \& Nystuen, 1982). However, redlining can also affect the non-poor and the whites. Thus, the problem cannot be simplified by studying poverty or racial discrimination (Sibley, 1995). It should be considered as the geography of social exclusion (Kasinitz, 1999). For example, research has shown that for various reasons, many banks are not willing to provide financial services to those in the South Bank area of Rotterdam. Only small financial institutions still grant loans in this area, but this process involves uneven conditions such as much higher interest rates, higher down payments, shorter funding periods and restricted restructuring rules (Aalbers, 2005b).

In Amsterdam, redlining does take place - not based on the consideration of mortgage repayment but rather on the availability of insurance. Insurance coverage rates among postal code areas were analysed and concluded that the area containing the red-light district in Amsterdam has different insurance implications (Aalbers, 2005b). By excluding certain neighbourhoods, insurance companies cause loan rejection: "no insurance, no mortgage" (Wagenaar, 1989, as cited in Aalbers, 2005b).

\subsection{Studies on Singapore's housing market}

A number of articles have applied hedonic regression as a means by which to analyse the private housing market in Singapore, covering aspects such as valuation, law, financing and architecture. Structural variables (e.g. size, age, level, green labelling; Deng, Li, \& Quigley, 2012), neighbourhood variables (e.g. proximity to health services churches and schools) and locational variables (e.g. proximity to ECP-East Coast Parkway, MRT and CBD) have been mentioned and studied in the research (Agarwal, Koo, \& Sing, 2015). In terms of loan financing, most papers have discussed the role of CPF-Central Provident Fund, the impact of government policy and the influence of foreign cash flow (Phang \& Wong, 1997; Phang, 2001; McCarthy, Mitchell, \& Piggott, 2002). None of the studies, however, have touched on the practice of redlining. As for the famous/infamous areas of Singapore, such as Little India, Chinatown and Geylang, most articles have examined aspects of urban development, ethnic heritage and social problems such as trafficking (Lee, 1996; Yea, 2013).

\section{Study area: Aljunied subzone, Geylang, Singapore}

Singapore's low crime rates and high healthcare standards contribute to its being deemed the safest city in the AsiaPacific region which have helped make Singapore one of 
the most desirable countries in which to live, attracting numerous investments from all over the world as a consequence (Mercer, 2016). However, it may be a surprise for investors and travellers to learn that prostitution is legal in Singapore as most people think of Singapore as a country that has ultrastrict laws and is spotless and conservative.

There are five planning regions and 28 districts in Singapore. The Geylang planning area is located on the eastern edge of the Central Region and is steps away from the central business district (CBD) of Singapore, see Figure 1. It is a $10 \mathrm{~km}^{2}$ region with approximately 150,000 residents.

The Aljunied planning subzone is the most famous subzone of the five subzones in the Geylang planning area; it is close to two major highways and Mass Rapid Transit (MRT) links. The area is $2.95 \mathrm{~km}^{2}$ with around 42,000 residents and is well-known for durian shops and overnight restaurants. Geylang Road locates at the centre of Geyalng area, which has a history that could be tracked back to 1842, with odd-number lanes (namely "Lorong" in Malay) in the north and even-numbered lanes (for example Lorong 2 and Lorong 4) that locates in the south. This area is also the main red-light district in Singapore. Prostitution activities are centred along Geylang Road and various other even-numbered lanes, together with commercial shops, temples, churches, mosques, residential apartments and even schools, see Figure 2.

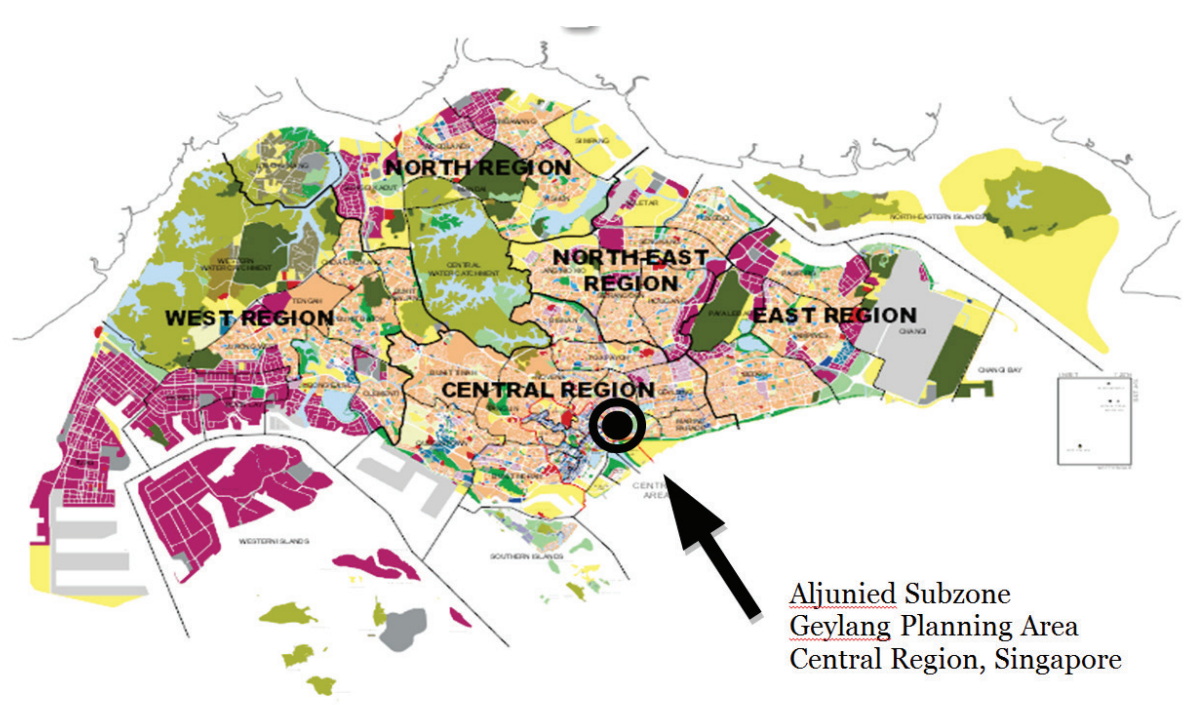

Figure 1. Location of Aljunied Subzone, Geylang, Singapore

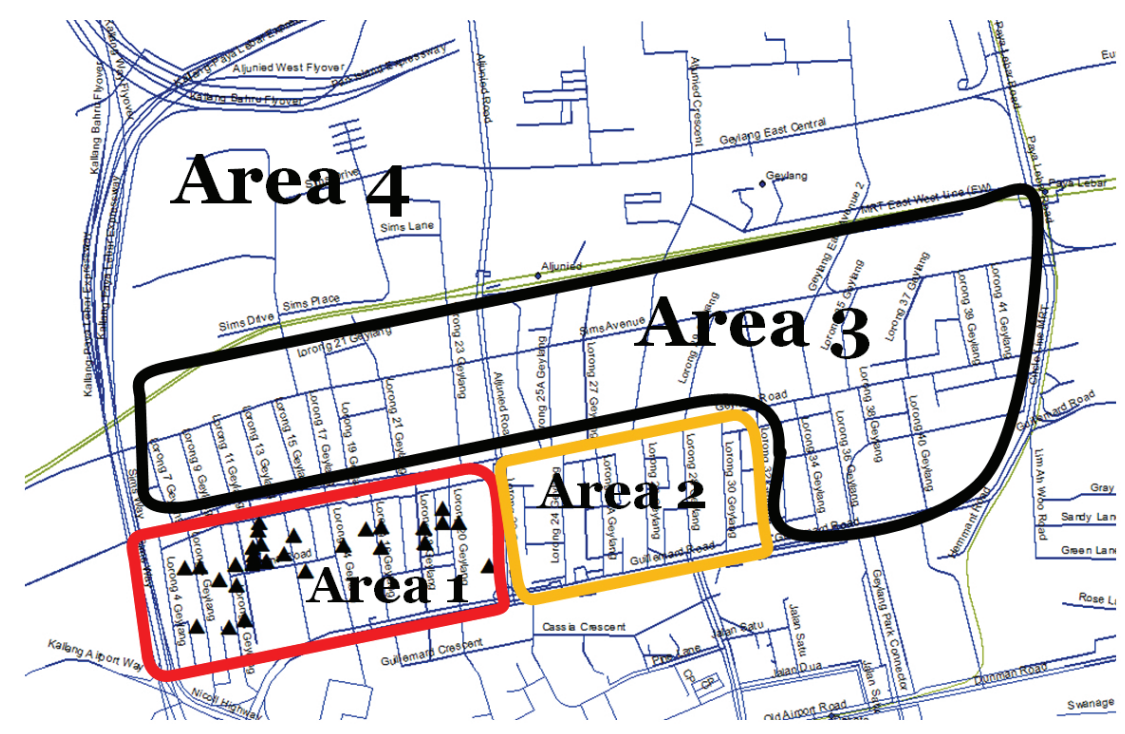

Figure 2. Details of Aljunied Subzone, Geylang

Area 1: Hotel and motel areas;

Area 2: Even-numbered lanes from Lorong 24 to Lorong 38;

Area 3: Even-numbered lanes from Lorong 40+, old-numbered lanes from Lorong 1 to Lorong 41, Geylang Road;

Area 4: Non-adjacent areas of red-light zones in Aljunied Subzone. 
Prostitution can be considered a major urban activity that affects other social, economic and political functions of an area. In general, there is a degree of ambiguity associated with whether prostitution activities in Singapore are legal. In fact, the authorities have legalized prostitution in certain areas, keeping it somewhat under control. The police unofficially tolerate and monitor "certified brothels" (Chin, 2013). Regulated brothels in even-numbered lanes carry on these activities and oversee that all sex workers undergo periodic health checks and have special work permits, the so-called "yellow card" (Lim, 2004). In addition to yellow card holders, freelancers and street workers - mostly foreigners from Thailand, Indonesia and China with tourist visas - contribute to the main sex industry workforce, and their activity is totally illegal (Kitiarsa, 2008). When the sun sets each evening, thousands of street workers appear, standing shoulder to shoulder along Geylang Road and dark even-numbered lanes.

It is undeniable that the nightlife industry makes a substantial contribution to the Geylang zone's economy. However, for a country that is well known for its cleanliness, beauty and low crime rates, Singapore's prostitution activity may surprise visitors and may even be ignored by residents who live nearby.

The real estate industry in Singapore is highly integrated in terms of planning, policymaking, rulings and so forth (Phang, 2001). Approximately $86 \%$ of Singaporeans live in public housing developed by the Housing and Development Board (HDB, 2017; Lum, 2002), and 80\% of the land in Singapore is owned by the government, including residential and commercial projects developed by both the government sector and private developers. Since the 1980s, the government has encouraged HDB owners, foreigners and unqualified HDB buyers to purchase from the private market (Chua, 2000). Getting into the private housing market is viewed as the ultimate goal of Singaporean owner-occupiers' housing careers (Tu, 2004).

There are two types of financing systems: one for the $\mathrm{HDB}$ and the other for the private residential market. The government is the major player in HDB financing, with commercial banks serving rich local or international buyers of private apartments (Bardhan, Datta, Edelstein, \& Sau Kim, 2003). In the Geylang zone, all HDB houses are located away from Lorongs and Geylang Road. The government reserves and plans this area for mainly private residential sites and commercial sites.

With its golden location and convenient services, this area should be a more attractive location for property buyers than it currently is. However, there are indications that this situation could change in the future. In January 2015, the Urban Redevelopment Authority collected feedback and advice for rezoning of the Geylang area from Lorong 2 to Lorong 24, which is considered the centre for vice activities (URA, 2015). As shown in Figure 2, hotels and motels are also concentrated in these areas (as shown in area 1). According to interviews with mortgage specialists from two local banks, DBS Bank and United Overseas Bank (UOB), residential properties that are located in even-numbered lanes from Lorong 2 to Lorong 22 are absolutely restricted for home financing from all local banks and most foreign banks, which means that mortgage specialists could reject the case on the spot without a risk officer's review due to moral and ethical concerns. Foreign banks (e.g. Maybank and RHB Bank) and other financial institutions (e.g. Hong Leong Financial Group and Singapura Finance) could provide 50\% to $70 \%$ financing, on a case-by-case basis (e.g. customers' relationship with the bank and reputation of the developers). However, the implications associated with the process of rezoning might prompt commercial banks to reconsider their current policies in these areas.

For properties located in even-numbered lanes from Lorong 24 to Lorong 38 as shown in Figure 2, certain banks require photographs of both daytime and nighttime surroundings for risk assessment. The approval rates largely depend on the bank's current policy, the customer's profile (relationship with the bank) and the developer's profile (local banks may have special tie-in packages up to a limited number of units for certain developers as a form of relationship support). After the rezoning proposal come out, new projects in this area will have the opportunity to receive normal financing from local banks as a support for this transformation.

For properties that are located in odd-numbered lanes from Lorong 1 to Lorong 41, evennumbered lanes from Lorong 40 and above and Geylang Road are generally not affected by financial constraints. However, certain banks (e.g. DBS) may require photographs of the subject property from time to time.

This paper proposes two hypotheses, based on the uniqueness of this study area. The first hypothesis is that homes that are located in the centre of red-light district (Area 1, see figure 2) have the lowest price per square foot (PSF) and the lowest rent per square foot (RSF) compared to homes in areas with no red-light districts. The second hypothesis is that there exists a redlining effect in the redlight district. As the study area is relatively small, properties that are located in Areas 1,2 and 3 are basically sharing the same or similar neighbourhood amenities such as schools, restaurants, hospitals and recreational attractions. Area 3 could be considered a mirror of the combination of Area 1 and Area 2. Both the PSF and RSF differences between Area 3 and Area 1 reflect the spatial impact of being located in the red-light district. However, if the difference in the PSF is much larger than the difference in the RSF, this might indicate the influence of redlining, as rent prices are not affected by financial constraints but purchase prices are.

\section{Methodology}

Every rental or purchase contract can be considered an equation in a supply and demand model in the market, with sales prices and rent prices being determined based on a collection of attributes such as structural variables, neighbourhood variables and locational variables. The 
hedonic pricing model is the most commonly used tool for analysing the relationship between the housing price and its attributes. Different functional forms have been widely mentioned in the literature.

The semi-logarithmic form is one of the most popular and largely applied functional forms that is recommended in the literature on the hedonic price model. In this paper, the natural logarithm of $y$ is taken as a dependent variable. The basic model is described as follows:

$$
\ln (Y)=f(S, N, L)+\varepsilon,
$$

where: $\ln (Y)$ is a dependent variable, which means a vector of logarithm property prices or rent prices; $S$ is a matrix of structural attributes (e.g. size, number of rooms, age); $N$ is a matrix of neighbourhood characteristics; $L$ is a matrix of locational data (e.g. distance to certain locations); and $\varepsilon$ is a vector of the error term.

Collinearity occurs when there are correlations among independent variables, and it will increase the standard errors among coefficients. It will affect the significance of independent variables as correlation will offset the impact of one other. The variance inflation (VIF) test was performed in Stata to detect collinearity in the models.

Another ordinary least squares (OLS) assumption is that the variance of the error term is constant, $\left(\varepsilon_{j}\right)=\sigma^{2}$, for all observations. Robust OLS was performed in Stata to control for heteroscedasticity.

According to Fahrländer (2006), real estate is heterogeneous because properties cannot be moved, and this characteristic leads to "locational differences". The similarity of building structures and geographical spatial dependence among properties always produce positive spatial autocorrelation problems (Wilhelmsson, 2002). However, as the study area is only $2.95 \mathrm{~km}^{2}$, all projects share the same or similar neighbourhood and locational variables; spatial dependency may not bias the results. Moran's I, a test for spatial autocorrelation, was performed to overcome this issue.

To test the equality of two regression coefficients from two different regression models (price regression model and rents regression model respectively), a standard Z-test is performed.

In addition to quantitative approaches, interviews were conducted with various stakeholders and relevant parties in the real estate industry, such as real estate agents, mortgage specialists from both local banks and foreign banks and mortgage brokers, to gain a better understanding of this area and the current housing situation.

\section{Empirical analysis}

\subsection{Data}

There are two main residential property markets in Singapore: the HDB market and the private market. The government of Singapore runs the HDB with strict regulations and controls; thus, the HDB market is excluded from this paper.

Two data sets, covering both sales and rental markets, are used in this paper. The first is a cross-section data set on all private residential apartment and condominium transactions in the Aljunied subzone from March 2013 through March 2016. Data on individual property prices, PSF and structural-related information (e.g. size and number of bedrooms, number of bathrooms, property age, floor level, completion status, and transaction period) were all gathered from the Urban Redevelopment Authority (URA) of Singapore, which is the national urban planning and management authority of Singapore. All records are caveats lodged by registered lawyers who handled the case.

The second data set contains information about the rental markets of the transacted projects in the first data set. This data set is web-clawed from www.propertyguru. $\mathrm{sg}$, one of the leading real estate advertisement websites with postings by certified real estate agents. The rental price obtained from the website is the guided price, the final price are signed privately between the owner and the tenant. The bargaining space are not much and generally based on their own agreement such as whether the utility cost is included, quality of the room at the visiting day, etc. In total there are 9 rounds of cooling measures, 7 out of 9 were introduced before this paper's sample period. Round 8 was introduced in June 2013 namely MAS introduces Debt Servicing Framework for property loans, which is the beginning period in the sample ${ }^{1}$.

Detailed Geographic Information System (GIS) coordinates of each record were captured using the World Geodetic System 1984 (WGS84) coordinates system to calculate the distance between subject properties and other geographic reference points.

As displayed in Tables 1 and Table 2, there are two panels used in this paper. For Panel A (Table 1), 1,414 transactions from March 2013 through March 2016 in the Aljunied subzone corresponded to 92 private residential projects. The minimum purchase price was around SGD 317,962 , and the most valuable unit was sold for SGD 2.5 million. The average sales price was SGD 814,008. Most properties sold in the range of SGD 650,000 to SGD 980,000 , with some outliers selling for over SGD 2 million. The PSF is the most common variable used by locals to compare prices; in this data set, the average property PSF in the Aljunied subzone was around SGD 1,280, and most of the properties were sold in the range of SGD 1,150 to SGD 1,450. The logarithm transformation of PSF is chosen as a dependent variable. In addition, the expected signs of the estimated coefficients are shown in Table 1.

\footnotetext{
1 To investigate the impact of cooling measures in the sample period, firstly, I have checked the transaction frequency by transaction date, and most of the transactions were done in the beginning of the sample period for all 4 locations, especially for Zone 1 , which is red-light area. Secondly, I have plotted the transaction prices and timeline for all observations for each Zone and there is no clear trend of declining, the effect of cooling measures was mainly on the transaction volumes instead of price for the study area, and most of the transactions for the apartments in the redlining region were transacted earlier than those not in the redlining region. Thirdly, I have generated dummy variables for 37 months, and take March 2013 as default, only 3 variables are significant at $1 \%$ and 9 variables are significant at $5 \%$.
} 
Table 1. Summary statistics of housing variables of Panel A

Panel A: Residential transactions from March 2013 through March 2016 (observations = 1,414; no. of projects = 92)

\begin{tabular}{|c|c|c|c|c|c|c|c|}
\hline Variable & Description & $\begin{array}{l}\text { Expected } \\
\text { sign }\end{array}$ & Freq & Mean & $\mathrm{SD}$ & Min & Max \\
\hline \multicolumn{8}{|c|}{ Variables to be explained } \\
\hline PSF & Price per square foot & & & $1,281.2$ & 220.9 & 610 & 1,800 \\
\hline LnPSF & $\ln (\mathrm{PSF})$ & & & & & & \\
\hline Price & Sale price of property & & & 814,008 & 243,205 & 317,962 & $2,500,000$ \\
\hline \multicolumn{8}{|c|}{ Basic Variables } \\
\hline Size & Size of the property & + & & 675.5 & 308.7 & 344 & 2,422 \\
\hline Age & Age of property in years & - & & 0.2 & 6.4 & -5 & 33 \\
\hline $\begin{array}{l}\text { FLcode } \\
\text { - FLcode } 1 \\
\text { - FLcode } 2 \\
\text { - FLcode } 3 \\
\text { - FLcode } 4\end{array}$ & $\begin{array}{l}\text { Dummy variable of floor level } \\
\text { Unit located on floors } 1-5 \\
\text { Unit located on floors } 5-10 \\
\text { Unit located on floors } 10-15 \\
\text { Unit located on floors } 15-20\end{array}$ & $\begin{array}{l}+ \\
+ \\
+\end{array}$ & $\begin{array}{l}741 \\
493 \\
118 \\
62\end{array}$ & 1.6 & 0.8 & 1 & 4 \\
\hline $\begin{array}{l}\text { Condo } \\
\text { - Condo } 1 \\
\text { - Condo } 0\end{array}$ & $\begin{array}{l}\text { Dummy variable, Condominium }=1 \text { if building } \\
\text { type is an apartment; condominium }=0 \text { if it is } \\
\text { an apartment }\end{array}$ & - & $\begin{array}{l}921 \\
493\end{array}$ & 0.65 & 0.48 & 0 & 1 \\
\hline $\begin{array}{l}\text { Freehold } \\
\text { - Freehold } 1 \\
\text { - Freehold } 0\end{array}$ & $\begin{array}{l}\text { Dummy variable, Freehold = } 1 \text { if ownership type } \\
\text { is freehold; freehold = } 0 \text { if } 99 \text {-year leasehold }\end{array}$ & + & $\begin{array}{l}536 \\
878\end{array}$ & 0.62 & 0.49 & 0 & 1 \\
\hline $\begin{array}{l}\text { Newsale } \\
\text { - Newsale } 1 \\
\text { - Newsale } 0\end{array}$ & $\begin{array}{l}\text { Dummy variable, Newsale = } 1 \text { if purchased from } \\
\text { developer }\end{array}$ & - & $\begin{array}{c}322 \\
1,092\end{array}$ & 0.77 & 0.42 & 0 & 1 \\
\hline $\begin{array}{l}\text { BUC } \\
- \text { BUC } 1 \\
- \text { BUC } 0\end{array}$ & $\begin{array}{l}\text { Dummy variable, } \mathrm{BUC}=1 \text { if building under } \\
\text { construction }\end{array}$ & - & $\begin{array}{c}262 \\
1,152\end{array}$ & 0.81 & 0.39 & 0 & 1 \\
\hline Latitude & Latitude of the property & - & & 1.315 & 0.003 & 1.31 & 1.32 \\
\hline MTH & Metres to the nearest hotel & - & & 417.4 & 277.6 & 9.9 & 1,053 \\
\hline \multicolumn{8}{|c|}{ Red-light district attributes } \\
\hline $\begin{array}{l}\text { Geylang } \\
\text { - Geylang } 1 \\
\text { - Geylang } 2 \\
\text { - Geylang } 3 \\
\text { - Geylang } 4\end{array}$ & $\begin{array}{l}\text { Dummy variable } \\
\text { Even lanes } 2-24 \\
\text { Even lanes } 24-38 \\
\text { Even lanes } 40-42 \text {, odd lanes } 1-441 \\
\text { Geylang Road } \\
\text { Other areas }\end{array}$ & $\begin{array}{l}+ \\
+ \\
+\end{array}$ & $\begin{array}{l}204 \\
301 \\
155 \\
754\end{array}$ & 3.03 & 1.15 & 1 & 4 \\
\hline
\end{tabular}

Table 2. Summary statistics of housing variables of Panel B

Panel B: Rental records, March 2016 (no. of observations = 941; no. of projects $=80$ )

\begin{tabular}{|c|c|c|c|c|c|c|c|}
\hline Variable & Description & Expected sign & Freq. & Mean & SD & Min & Max \\
\hline \multicolumn{8}{|c|}{ Variable to be explained } \\
\hline Rental & Requested rental of property & & & 2,307 & 809.9 & 230 & 5,500 \\
\hline Rentsf & Requested rental of property/size & & & & & & \\
\hline LnRentsf & $\ln$ (Rentsf) & & & 7.68 & 0.39 & 5.44 & 8.61 \\
\hline \multicolumn{8}{|c|}{ Basic variables } \\
\hline Size & Size of the property & - & & 607.14 & 356.4 & 50 & 2,800 \\
\hline Age & Age of the property & - & & 5.9 & 7.2 & 1 & 34 \\
\hline RoomType & Dummy variable & & & 3.56 & 2.82 & 1 & 10 \\
\hline - RoomType 1 & 1 bedroom with 1 bathroom & & 355 & & & & \\
\hline - RoomType 2 & 1 bedroom with 2 bathrooms & NA & 47 & & & & \\
\hline - RoomType 3 & 2 bedrooms with 1 bathroom & NA & 150 & & & & \\
\hline - RoomType 4 & 2 bedrooms with 2 bathrooms & NA & 99 & & & & \\
\hline
\end{tabular}


End of Table 2

\begin{tabular}{|c|c|c|c|c|c|c|c|}
\hline Variable & Description & Expected sign & Freq. & Mean & $\mathrm{SD}$ & Min & $\operatorname{Max}$ \\
\hline - RoomType 5 & 3 bedrooms with 2 bathrooms & NA & 129 & & & & \\
\hline - RoomType 6 & $4+$ bedrooms with $2+$ bathrooms & & 30 & & & & \\
\hline - RoomType 7 & $\begin{array}{l}\text { Renting a bed, sharing one room } \\
\text { with } 2,4 \text { or } 6 \text { others }\end{array}$ & + & 5 & & & & \\
\hline - RoomType 8 & $\begin{array}{l}\text { Renting a maid's room with no } \\
\text { window and no bathroom }\end{array}$ & + & 6 & & & & \\
\hline - RoomType 9 & $\begin{array}{l}\text { Renting a common room/guest } \\
\text { room with no bathroom }\end{array}$ & + & 54 & & & & \\
\hline - RoomType 10 & Renting a master bedroom & + & 66 & & & & \\
\hline \multicolumn{8}{|c|}{ Red-light district attributes } \\
\hline Geylang & Dummy variable & & & & & & \\
\hline - Geylang 1 & Even lanes 2-24 & & 51 & 2.63 & 0.83 & 1 & 4 \\
\hline - Geylang 2 & Even lanes $24-38$ & + & 403 & & & & \\
\hline - Geylang 3 & $\begin{array}{l}\text { Even lanes } 40-42 \text {, odd lanes } \\
1-41 \text {, Geylang Road }\end{array}$ & + & 328 & & & & \\
\hline - Geylang 4 & Other areas & + & 159 & & & & \\
\hline
\end{tabular}

All variables used in the hedonic regression for the rental market, with the expected signs of the estimated coefficients, are displayed in Table 2 . The average rent price was about SGD 2,307 in the area studied. The expectation is that the RoomType dummy variable will have an impact on rent prices and the rent per square foot (RSF). That is, a larger apartment will charge a higher rent price but a lower RSF. As for the Geylang dummy variable, if $\mathrm{Hy}-$ pothesis 1 holds, the RSF should be much lower in Area 1 and Area 2. If Hypothesis 2 holds, there should be a big difference in the coefficients of the Geylang dummy variables for regressions from Panel A and Panel B. The natural logarithm of RSF is used as a dependent variable, based on the Box-Cox test. ${ }^{2}$

\subsection{Results and discussion}

As constrained by dataset, this paper performed a crosssection hedonic regression instead of difference-in-difference analysis. The hedonic regression results for both property and rental markets are presented in Table 3, Table 4 and Table 5. Based on the goodness-of-fit criteria, the standard $R^{2}$ is used to guide the choice for specification of the OLS model. Because the natural logarithms of PSF and RSF are used, the estimated coefficients of the explanatory dummy variables are in semi-logarithmic form. The true value of the percentage impact is calculated based on Halvorsen and Palmquist's (1980) method, using formula

2 Moran's I is around 0.4. Weight matrix $=\mathrm{k}$ Nearest Neighbours $(\mathrm{kNN})$ algorithm $(\mathrm{k}=15)$.

Three spatial models were performed in MATLAB: the spatial autoregressive model ( $\mathrm{z}$ value of rho is 0.87 , not significant), the spatial error model (lambda $=0.66$, significant) and the spatial Durbin model (SDM). The SDM has the highest loglikelihood value, so the SDM fits best. However, the coefficients from the SDM are not significantly different from the OLS as the study area is very small.
Table 3. Transaction price per square foot for 1,414 apartments: basic variables Robust OLS model

\begin{tabular}{|c|c|c|c|c|c|}
\hline LnPSF & Coefficient & $\mathrm{t}$ & $p>t$ & \multicolumn{2}{|c|}{$95 \% \mathrm{CI}$} \\
\hline Size & -0.00 & -24.82 & 0.00 & -0.00 & -0.00 \\
\hline Age & -0.02 & -30.26 & 0.00 & -0.02 & -0.01 \\
\hline BUC & 0.09 & 4.36 & 0.00 & 0.05 & 0.12 \\
\hline \multicolumn{6}{|l|}{ FLcode } \\
\hline 2 & 0.03 & 6.01 & 0.00 & 0.02 & 0.04 \\
\hline 3 & 0.05 & 5.96 & 0.00 & 0.04 & 0.06 \\
\hline 4 & 0.08 & 7.60 & 0.00 & 0.06 & 0.10 \\
\hline \multicolumn{6}{|l|}{$\begin{array}{l}\text { Condo* }^{*} \\
\text { Freehold }\end{array}$} \\
\hline 01 & 0.10 & 6.42 & 0.00 & 0.07 & 0.12 \\
\hline 10 & 0.16 & 7.71 & 0.00 & 0.12 & 0.20 \\
\hline 11 & \multicolumn{5}{|c|}{ NA } \\
\hline Freehold & 0.10 & 6.66 & 0.00 & 0.07 & 0.13 \\
\hline Newsale & -0.06 & -5.92 & 0.00 & -0.09 & -0.04 \\
\hline MTH & -0.00 & 8.22 & 0.00 & 0.00 & 0.00 \\
\hline Longitude & 5.01 & 3.55 & 0.00 & 2.27 & 7.88 \\
\hline Latitude & -21.12 & -9.07 & 0.00 & -25.69 & -16.55 \\
\hline \multicolumn{6}{|l|}{ Geylang } \\
\hline 2 & 0.04 & 4.77 & 0.00 & 0.02 & 0.06 \\
\hline 3 & 0.14 & 11.58 & 0.00 & 0.11 & 0.16 \\
\hline 4 & 0.13 & 16.02 & 0.00 & 0.11 & 0.14 \\
\hline$R^{2}$ & \multicolumn{5}{|c|}{0.8453} \\
\hline$R_{a d j}^{2}$ & \multicolumn{5}{|c|}{0.8436} \\
\hline
\end{tabular}

Note: $\mathrm{BUC}=$ building under construction; $\mathrm{CI}=$ confidence interval; $\mathrm{FL}=$ floor level; MTH = distance in metres to the nearest hotel; OLS = ordinary least squares; PSF = price per square foot. 
$\left(e^{\beta}-1\right) \cdot 100$, where $\beta$ is the estimated coefficient of dummy variables. To test the equality of the two regression models, a manually z-test has been performed. According to the statistical result shown in Table 5, their differences are significant.

\subsubsection{Basic variables of the property market}

For the property market, the OLS model explains approximately $85 \%$ of the variance in PSF, and most of the parameters have the expected signs, see Table 1 and Table 3.

Size is expected to have a negative relationship with PSF because the kitchen and bathrooms are the most expensive parts in the construction and developers tend to price smaller units higher for maximized overall profit. Although the estimated variables have the expected signs and are significant, a larger impact is expected. As shown in Table 1, most apartments transacted in Panel A are smaller than $800 \mathrm{ft}^{2}$, with a mean of $675 \mathrm{ft}^{2}$. There are a greater number of smaller units in the observations, leading to a less obvious impact of size on PSF.

A similar result is found for the age of the apartment, with a one-year increase in the property's age leading to a $2 \%$ decrease in its PSF. The sign of the BUC is different from what is expected. Normally, BUC properties are sold at a discount to attract buyers because the buyers have only plot plans and floor plans on which to make their decision to purchase. However, in the study area, BUC properties were transacted at a $9 \%$ premium. This is also a positive sign, showing customers' confidence in future markets. Properties located on higher floor levels have higher property values. Compared with units on floor levels 1 to 5, buyers pay $8 \%$ more for units on floor levels 15 to 20 because units on higher floor levels have better lighting, less traffic noise pollution and better views.

Private residential properties can be classified into one of two types based on site area and number of functional common facilities. Only projects with full facilities such as tennis courts, swimming pools and larger site areas can be defined as condominiums, otherwise they are apartments. According to the regression results shown in Table 3, if the property of a project is classified as an apartment, there is an $11 \%$ discount compared with a full facility condominium.

There are two types of ownership: freehold properties and 99-year leasehold projects. Freehold properties are generally more valuable than leasehold properties but are mostly apartments, whereas leasehold projects are always developed by well-known developers and have a better location and are of better quality. A leasehold apartment is taken as the default dummy variable. Freehold condominiums are sold around $10 \%$ more, and leasehold condominiums are the most valuable properties in the data set.

The MTH locational variable measures the distance in metres to the nearest hotel: the closer the distance to the hotel, the higher the chance of witnessing street sex workers at night. The sign is negative as expected, but the impact was very small, perhaps because of the limited size of the study area. The coefficient of variable y shows that in the Aljunied area, properties on the west side are more valuable than those located on the east.

\subsubsection{Basic variables in the rental market}

As shown in Table 4 by the hedonic regression results of data set "Panel B: Rental Records" (Table 2), the robust OLS model explains $80 \%\left(R_{a d j}^{2}=79.5 \%\right)$ of the variance in rental prices.

Similar to the property market, an increase in size and age will lead to a lower RSF. Compared with the property market, age has a greater effect on the RSF. One possible reason is that all projects under construction are not available in the market and for existing projects. Tenants prefer to rent new apartments because of their better facilities and living conditions. Utility bills are generally not included in rent prices, and tenants pay for them monthly.

The nine estimated coefficients of the RoomType dummy variable reflect the owners' rental conditions for different room types. Of the 10 RoomTypes, renting a bed in a shared room (RoomType 7) is the most profitable rental arrangement for a landlord, with an increase of over $60 \%$ compared with renting an entire one-bedroom apartment (one bedroom and one living room) with one shower (RoomType 1). The least profitable arrangement for a landlord is RoomType 2 (one-bedroom apartment with two showers), in which the entire unit is rented.

Table 4. Market rental price per square foot for 941 apartments: basic variables Robust OLS model

\begin{tabular}{|c|c|c|c|c|c|}
\hline Lnrentsf & Coefficient & $t$ & $p>t$ & \multicolumn{2}{|c|}{$95 \%$ CI } \\
\hline \multicolumn{6}{|l|}{ RoomType } \\
\hline 2 & -0.12 & -5.34 & 0.00 & -0.17 & -0.08 \\
\hline 3 & 0.01 & 0.82 & 0.41 & -0.02 & 0.04 \\
\hline 4 & 0.03 & 1.39 & 0.17 & -0.01 & 0.08 \\
\hline 5 & 0.19 & 6.16 & 0.00 & 0.13 & 0.26 \\
\hline 6 & 0.39 & 9.04 & 0.00 & 0.31 & 0.48 \\
\hline 7 & 0.60 & 8.91 & 0.00 & 0.48 & 0.73 \\
\hline 8 & 0.43 & 7.08 & 0.00 & 0.31 & 0.55 \\
\hline 9 & 0.22 & 7.53 & 0.00 & 0.16 & 0.27 \\
\hline 10 & 0.11 & 4.56 & 0.01 & 0.06 & 0.15 \\
\hline Size & -0.001 & -21.93 & 0.00 & -0.00 & -0.00 \\
\hline Age & -0.004 & -3.46 & 0.00 & -0.01 & -0.00 \\
\hline \multicolumn{6}{|l|}{ Geylang } \\
\hline 2 & 0.03 & 1.13 & 1.19 & -0.01 & 0.7 \\
\hline 3 & 0.8 & 3.52 & 0.00 & 0.03 & 0.12 \\
\hline 4 & 0.14 & 5.96 & 0.00 & 0.09 & 0.18 \\
\hline$R^{2}$ & \multicolumn{5}{|c|}{0.7978} \\
\hline$R_{a d j}^{2}$ & \multicolumn{5}{|c|}{0.7948} \\
\hline
\end{tabular}


Compared with RoomType 1, RoomType 2 has a $12 \%$ decrease in RSF. Tenants pay less because in such a limited space, the increase in the number of bathrooms or showers will reduce the utility of the living space.

RoomType 9 is a maid's room and could also be a boom shelter with or without a window, a proper door or a private bathroom. Normally, the maid's room is 40 $\mathrm{ft}^{2}$ to $60 \mathrm{ft}^{2}$. As shown in the regression results, this is the second most profitable rental arrangement for a landlord. The RSF for renting an entire apartment with more than three bedrooms and two bathrooms ranks the third highest, with a $39 \%$ increase compared with RoomType 1 . The higher values of estimated coefficients for RoomTypes 7 , 8,9 and 10 show that renting rooms is the most profitable rental arrangement for landlords. Larger apartments with more bedrooms and bathrooms can be rented in different ways, such as renting to a second-hand landlord who then rents beds or rooms separately to earn the difference in rent.

\subsubsection{Red-light district attributes}

The estimated coefficients of the dummy variables show the same signs as expected, see Table 1, Table 2 and Table 5. Geylang 1 is the dummy variable for properties located along even-numbered lanes from Lorong 2 to Lorong 22. This area has many hotels and motels (Figure 2), and at night, streetwalkers stand shoulder to shoulder in this area, waiting to engage in conversation. Interviews with Martin $\mathrm{Gu}$, a regional senior real estate agent from Pro$\mathrm{pNex}$ (one of the leading real estate agencies in Singapore and Southeast Asia) revealed that among four red-light district-related attributes, residential properties located in Geylang 1 have the lowest PSF and the lowest RSF. The regression result indicates that the existence of red-light districts negatively influences the regional residential housing market, as assumed.

Properties in this area are under restricted financing. In general, commercial banks are unwilling to provide mortgages in a vice area because of certain concerns such as low turnover rate, low transaction volume, potential money laundering risk and reputation. To enter the market, buyers must either pay fully in cash or turn to other financial institutions for help, such as Hong Leong Finance and Singapura Finance, with higher (perhaps more than twice as high) interest rates. According to interviews with Helen $\mathrm{Hu}$, a senior female agent from $\mathrm{PN}$ who is a rental market specialist in this area, owners in this area buy properties for investment purposes, and some buy- ers prefer to use the same agent during the transaction process to find the tenants and are more flexible about the criteria for potential tenants (e.g. they allow lease times of less than one year, allow residents to partition rooms and limited investigation of tenants' occupations).

The Geylang 2 dummy variable refers to properties located along the even-numbered lanes from Lorong 24 to Lorong 38, see Figure 2. In the property market, there is a $4 \%$ increase in the PSF for properties in Geylang 2 compared with those that are located in the red-light district, and the premium is highly substantial. In the rental market, there is also an increase in the RSF for rental properties in Geylang 2 (of around 3\%), see Table 5. Although the coefficient is not significant at $5 \%$, a $95 \%$ confidence interval (CI) falls into a range from -0.01 to 0.07 , representing a range of only a $1 \%$ decrease in RSF to a $6 \%$ increase, see Table 4 . The coefficients of both sale and rental properties located in and near the red-light district reflect that Hypothesis 1 holds - that is, proximity to the redlight district negatively affects both property and rental markets.

The areas of Geylang 1 and Geylang 2 are split by Aljunied Road, a main traffic road with many bus lanes connecting to the CBD and east coast areas, see Figure 2. In addition to working in licenced brothels, most street sex workers are mobile and walk to Geylang 2 to minimize competition and to avoid police checks. This area could also be considered as a spatial spillover of the main redlight district.

Geylang 2 has also been rezoned, and it is soon to be transformed from a residential area into commercial sites. To support the government's policy, local banks such as DBS and OCBC are ready to finance some of the projects, providing up to $80 \%$ financing for qualified buyers up to a certain number of units (e.g. financing for 10 units of a residential project with 50 units in total).

According to interviews with the senior mortgage specialists from DBS Bank and UOB Bank, loan approval in this area is very subjective. Generally, the risk assessment takes three aspects into consideration: the characteristics of the apartment, the profile of the borrower and the reputation of the developer (relationship with the developer). Risk control department sometimes require the mortgage specialist to submit photographs of the street, for both day and night, as a reference for analysing the risk of selling if foreclosure happens in the future. What's more, the relationships between banks verses customers and banks verses developers also matter.

Table 5. The impact of red-light district attributes on both property and rental markets

\begin{tabular}{|c|c|c|c|c|c|}
\hline \multicolumn{2}{|c|}{ Property market } & \multicolumn{2}{|c|}{ Rental market } & \multicolumn{2}{c|}{ Equality Test } \\
\hline Geylang & Coefficient & Geylang & Coefficient & 2 & Z-Score \\
\hline 2 & 0.04 & 2 & 0.03 & 3 & 212 \\
\hline 3 & 0.14 & 3 & 0.08 & 4 & -67 \\
\hline 4 & 0.13 & 4 & 0.14 & 4 \\
\hline
\end{tabular}


As for Geylang 3, the odd-numbered lanes from Lorong 1 to Lorong 41, the even-numbered lanes from Lorong 40+ and Geylang Road (which splits odd- and even-numbered lanes), are the areas that are adjacent (and closest) to the central red-light zone, see Figure 2. The estimated coefficients for both the property market and the rental market are significant and robust. Location wise, Geylang 3, which is adjacent to the red-light district, could be considered a mirror of the combination of Geylang 1 and Geylang 2. But for Geylang 3, current home financing constraints do not exist in this area for all banks; that is, customers can borrow up to $80 \%$ of the valuation price from both local and foreign commercial banks.

The coefficients of Geylang 3 for the property market and the rental market capture the effects of both locational and neighbourhood variables as shown in Table 5. The PSF and RSF in Geylang 3 are much higher than those in Geylang 1, with increases of $14 \%$ for the PSF and $7.6 \%$ for the RSF. The difference between the rental market and the property market is obvious - around $6.4 \%$, which means that properties that locate is Geylang 1 has a 6.4\% lower PSF than RSF. Given the current redlining practice in Geylang 1, this result might indicate that redlining could be one of the factors influencing the property purchasing market, where Hypothesis 2 holds.

Properties in Geylang 4 are far away from the redlight district and are not affected by home financing constraints. According to the coefficients of Geylang 4 for the property market and the rental market, the PSF and the RSF increased by $12 \%$ and $13 \%$, respectively, compared with properties in Geylang 1.

\section{Summary and conclusions}

The existence of Geylang, the large, vibrant red-light district located just outside Singapore's CBD has its roots in an earlier age when there was a mainly inward migration of men to Singapore. Policies related to prostitution have been developed several times in the past century by British colonial and Singaporean governments. Currently, brothels are tolerated in certain zones in Geylang. In addition to an increasing number of police officers patrolling the area on foot, new surveillance cameras have also been installed in dark lanes to deter vice activities.

There are 40,000 residents living in the Aljunied subzone. Most vice activities are carried out in the Geylang area. Many countries have criminalized prostitution, and its existence has always been associated with a bundle of problems that negatively affects the quality of life within communities, and the impact of these problems may also spread to adjacent areas. This paper examines the following: the influence of red-light areas on property and rental markets, and the impact of redlining on these grey areas.

Two panels of data covering both sales and rental markets were used: the hedonic model was applied to 1,414 records of apartment and condominium transactions from March 2013 through March 2016 for sales markets analysis, and 912 records from the PropertyGuru website were selected to analyse the rental markets.
Our results indicate that the existence of Singapore's red-light district affects both residential purchase and rental markets and has a spatial spillover impact on the neighbourhood. The properties located in even-numbered lanes from Lorong 2 to Lorong 22 have both the lowest PSF and rent. Within the study area, the farther a property is located from the red-light district, the higher the PSF and rent.

Another finding is that the existence of Singapore's red-light district affects property markets to a greater extent than rental markets. Because the study area is relatively small, properties that are located in Geylang 1, Geylang 2 and Geylang 3 basically share the same or similar neighbourhood amenities such as schools, restaurants, hospitals and recreational attractions. Geographically, Geylang 3 could be considered a mirror of the combination of Geylang 1 and Geylang 2. The differences in the PSF and the rent between Geylang 3 and Geylang 1 reflect the spatial impact of being located in the red-light district. For properties that are located in Geylang 3, the difference in the PSF between two markets are around 6.4\%, which is much higher than properties that are located in Geylang 1,2 or 4 .

However, from historical perspective, it might be that the real estate prices were low at the beginning, which then caused single men to move there but subsequently caused prostitutes to become active in the area. Therefore, lower prices might have contributed to redlining historically ${ }^{3}$. But given the current situation with redlining practice, this paper find that, this is a negative relationship between redlining and purchases prices, as rent prices are not affected by financial constraints but purchase prices are.

\section{References}

Aalbers, M. B. (2005a). Place-based social exclusion: redlining in the Netherlands. Area, 37(1), 100-109. https://doi.org/10.1111/j.1475-4762.2005.00609.x

Aalbers, M. B. (2005b). Who's afraid of red, yellow and green?: Redlining in Rotterdam. Geoforum, 36(5), 562-580.

https://doi.org/10.1016/j.geoforum.2004.11.002

Aalbers, M. B. (2009). Why the community reinvestment act cannot be blamed for the subprime crisis. City \& Community, 8(3), 346-350.

https://doi.org/10.1111/j.1540-6040.2009.01292_2.x

Aalbers, M. B., \& Deinema, M. (2012). Placing prostitution. City, 16(1-2), 129-145. https://doi.org/10.1080/13604813.2012.662370

Agarwal, S., Koo, K. M., \& Sing, T. F. (2015). Impact of electronic road pricing on real estate prices in Singapore. Journal of Urban Economics, 90, 50-59.

https://doi.org/10.1016/j.jue.2015.09.004

Ashworth, G. J., White, P. E., \& Winchester, H. P. M. (1988). The red-light district in the West European city: a neglected aspect of the urban landscape. Geoforum, 19(2), 201-212. https://doi.org/10.1016/S0016-7185(88)80029-0

Bardhan, D. A., Datta, R., Edelstein, R. H., \& Sau Kim, L. (2003). A tale of two sectors: upward mobility and the private housing market in Singapore. Journal of Housing Economics, 12(2), 83105. https://doi.org/10.1016/S1051-1377(03)00016-0

3 Thanks to the referee's comments about correlation and causation. 
Chin, C. B. (2013). Cosmopolitan sex workers: women and migration in a global city. Oxford University Press.

Chua, B. H. (2000). Public housing residents as clients of the state. Housing Studies, 15(1), 45-60. https://doi.org/10.1080/02673030082469

Del Casino Jr., V. J., \& Hanna, S. P. (2003). Mapping identities, reading maps: the politics of representation in Bangkok's sex tourism industry. In S. P. Hanna \& V. J. Del Casino Jr. (Eds.), Mapping Tourism (pp. 161-185). Minneapolis: University of Minnesota Press.

Deng, Y., Li, Z., \& Quigley, J. M. (2012). Economic returns to energy-efficient investments in the housing market: evidence from Singapore. Regional Science and Urban Economics, 42(3), 506-515. https://doi.org/10.1016/j.regsciurbeco.2011.04.004

Fahrländer, S. (2006). Semiparametric construction of spatial generalized hedonic models for private properties. Schweizerische Zeitschrift für Volkswirtschaft und Statistik, 142(4), 501-528.

Halvorsen, R., \& Palmquist, R. (1980). The Interpretation of dummy variables in semilogarithmic equations. The American Economic Review, 70(3), 474-475.

HDB. (2017). About us. Housing \& Development Board, Singapore Government, Singapore. Retrieved from http://www. hdb.gov.sg/cs/infoweb/about-us

Holloway, S. R. (1998). Exploring the neighborhood contingency of race discrimination in mortgage lending in Columbus, Ohio. Annals of the Association of American Geographers, 88(2), 252-276. https://doi.org/10.1111/1467-8306.00093

Hubbard, P. (2004). Revenge and injustice in the neoliberal city: uncovering masculinist agendas. Antipode, 36(4), 665-686. https://doi.org/10.1111/j.1467-8330.2004.00442.x

Hubbard, P., \& Whowell, M. (2008). Revisiting the red light district: still neglected, immoral and marginal?. Geoforum, 39(5), 1743-1755. https://doi.org/10.1016/j.geoforum.2008.05.003

Jakobsson, N., \& Kotsadam, A. (2013). The law and economics of international sex slavery: prostitution laws and trafficking for sexual exploitation. European Journal of Law and Economics, 35(1), 87-107. https://doi.org/10.1007/s10657-011-9232-0

Kantor, A. C., \& Nystuen, J. D. (1982). De facto redlining a geographic view. Economic Geography, 58(4), 309-328. https://doi.org/10.2307/143457

Kasinitz, P. (1999). Red Hook: The paradoxes of poverty and place in Brooklyn. Research in Urban Sociology, 5, 253-274. https://doi.org/10.1016/S1047-0042(00)80029-X

Kitiarsa, P. (2008). Thai migrants in Singapore: state, intimacy and desire. Gender, Place \& Culture, 15(6), 595-610. https://doi.org/10.1080/09663690802518495

Lee, S. L. (1996). Urban conservation policy and the preservation of historical and cultural heritage: the case of Singapore. Cities, 13(6), 399-409. https://doi.org/10.1016/0264-2751(96)00027-3

Lim, G. (2004). Invisible trade: high-class sex for sale in Singapore. Singapore: Monsoon Books.

Lum, S. K. (2002). Market fundamentals, public policy and private gain: house price dynamics in Singapore. Journal of Property Research, 19(2), 121-143.

https://doi.org/10.1080/09599910210125232
Marttila, A.-M. (2008). Desiring the 'Other': prostitution clients on a transnational red-light district in the border area of Finland, Estonia and Russia. Gender, Technology and Development, 12(1), 31-51. https://doi.org/10.1177/097185240701200104

McCarthy, D., Mitchell, O. S., \& Piggott, J. (2002). Asset rich and cash poor: retirement provision and housing policy in Singapore. Journal of Pension Economics and Finance, 1(3), 197-222. https://doi.org/10.1017/S1474747202001130

Mercer. (2016). 2016 Quality of living rankings, Top 5 by Regions. Mercer LLC. Retrieved from https://www.mercer.com/ newsroom/2016-quality-of-living-survey.html

Neave, M. (1988). The failure of prostitution law reform. Australian \& New Zealand Journal of Criminology, 21(4), 202-213. https://doi.org/10.1177/000486588802100403

Nesiba, R. F. (1996). Racial discrimination in residential lending markets: why empirical researchers always see it and economic theorists never do. Journal of Economic Issues, 30(1), 51-77. https://doi.org/10.1080/00213624.1996.11505766

Phang, S.-Y. (2001). Housing Policy, wealth formation and the Singapore economy. Housing Studies, 16(4), 443-459. https://doi.org/10.1080/02673030120066545

Phang, S.-Y., \& Wong, W.-K. (1997). Government policies and private housing prices in Singapore. Urban Studies, 34(11), 1819-1829. https://doi.org/10.1080/0042098975268

Ross, S. L., \& Tootell, G. M. B. (2004). Redlining, the community reinvestment act, and private mortgage insurance. Journal of Urban Economics, 55(2), 278-297. https://doi.org/10.1016/S0094-1190(02)00508-9

Ryder, A. (2004). The changing nature of adult entertainment districts: between a rock and a hard place or going from strength to strength?. Urban Studies, 41(9), 1659-1686. https://doi.org/10.1080/0042098042000243093

Sibley, D. (1995). Geographies of exclusion: society and difference in the west. London: Routledge.

$\mathrm{Tu}$, Y. (2004). The dynamics of the Singapore private housing market. Urban Studies, 41(3), 605-619. https://doi.org/10.1080/0042098042000178708

URA. (2015). Proposed change in land use zoning of Lorongs 4-22 Geylang to better manage issues arising from conflicting uses. Urban redevelopment authority, Singapore government, Singapore. Retrieved from https://www.ura.gov.sg/uol/mediaroom/news/2015/jan/pr15-02

Wagenaar, M. (1989). Postcode-uitsluiting is geen nieuw verschijnsel en ook geen incident [Zip code exclusion is not a new phenomenon and not an incident]. Het Parool, March 8.

Wilhelmsson, M. (2002). Spatial models in real estate economics. Housing, Theory and Society, 19(2), 92-101. https://doi.org/10.1080/140360902760385646

Winchester, H. P. M., \& White, P. E. (1988). The location of marginalised groups in the inner city. Environment and Planning D: Society and Space, 6(1), 37-54. https://doi.org/10.1068/d060037

Yea, S. (2013). Mobilising the child victim: the localisation of human trafficking in Singapore through global activism. Environment and Planning D: Society and Space, 31(6), 988-1003. https://doi.org/10.1068/d15411 